\title{
LAS SOCIEDADES PREHISPÁNICAS TARDÍAS EN LA REGIÓN SEPTENTRIONAL DEL CENTRO DE ARGENTINA (SIERRAS DEL NORTE, CÓRDOBA). AVANCES A SU CONOCIMIENTO DESDE LOS RECURSOS VEGETALES
}

\author{
LATE PRE-HISPANIC SOCIETIES IN NORTHERN REGION \\ OF THE CENTRAL ARGENTINA (SIERRAS DEL NORTE, CÓRDOBA). \\ APPROACHES FROM PLANT RESOURCES
}

\author{
Andrea Recalde y Laura López ${ }^{2}$
}

\begin{abstract}
El período Prehispánico Tardío (ca. 400-1550 d.C.) se caracteriza porque las comunidades que ocuparon el sector centro-oeste de las Sierras de Córdoba llevaron adelante estrategias y patrones de subsistencia flexibles, donde la movilidad estacional desempeñó un papel fundamental, puesto que permitía un uso diversificado del paisaje mediante la explotación de diversos ambientes, los cuales proporcionaban recursos distribuidos de manera heterogénea a lo largo del año. En este contexto, la agricultura, desarrollada a pequeña escala y con escasa tecnificación, no regía la vida de los grupos prehispánicos, sino que estaba supeditada a la ausencia de otras alternativas al inicio de la estación productiva. Los datos recuperados hasta el momento en el sector septentrional de la región, concretamente en Cerro Colorado (Sierras del Norte), ponen en evidencia procesos históricos similares a la región centro-oeste con respecto al tipo de estrategias económicas y, fundamentalmente, las formas de agricultura (de pequeña escala y a secano). Sin embargo, de manera gradual la información acumulada indica que estas estrategias produjeron paisajes diferentes caracterizados por la variabilidad en el manejo de distintas especies vegetales silvestres y domesticadas, en tanto trajo aparejada la implementación de estrategias variadas vinculadas con los tiempos agrícolas y las pautas de movilidad.
\end{abstract}

Palabras claves: centro de Argentina, Sierras del Norte, período Prehispánico Tardío, recursos vegetales.

The Late Pre-Hispanic Period (ca. 400-1550 AD) is characterized by communities that occupied the central-western area of the Sierras of Córdoba and who developed flexible strategies and patterns of subsistence where seasonal mobility was central. This seasonal mobility allowed exploiting different environments, which provided resources throughout the year. In this context, agriculture, which was small-scale and with scarce or no-mechanization, did not regulate the life of the pre-Hispanic communities but was subject to the absence of other alternatives at the beginning of the productive season. Data recovered in the northern region of Sierras of Córdoba, specifically in Cerro Colorado (Sierras del Norte), reveal similar historical processes to those in the central-western region regarding the type of subsistence strategies and, fundamentally, of (small-scale dryland) agricultural practice. However, the data gathered gradually indicate that these economic strategies produced different landscapes characterized by different ways in handling wild and domesticated plant species. Therefore dissimilar strategies related to agricultural times and mobility patterns were carried out.

Key words: Central Argentina, Sierras del Norte, Late Pre-Hispanic Period, plant resources.

Estudios arqueológicos llevados a cabo durante los últimos años en el sector serrano de la provincia de Córdoba (centro de Argentina) han dado cuenta que los grupos humanos que habitaron la región durante el período Prehispánico Tardío (400-1550 d.C.) (en adelante PPT) se caracterizaron por poseer una alta movilidad residencial con momentos de fusión y fisión como estrategias centrales para la reproducción social (Medina et al. 2016; Pastor et al. 2012). La agricultura de pequeña escala, desarrollada a secano, y de escasa tecnificación (ausencia de rasgos arquitectónicos de sistemas de riego y de retención del suelo, entre otros), lejos de transformar la forma de vida de los grupos, constituyó una de las prácticas llevadas adelante en el proceso de diversificación e intensificación del consumo de recursos iniciados hacia, por lo menos, el final del Holoceno Medio-inicio del Holoceno Tardío (40003000 a.p.) (López et al. 2014; Pastor et al. 2012). En este marco, a partir del PPT se desarrollaron

1 CONICET-Área de Arqueología del Instituto de Estudio Históricos/ Centro de Estudios Históricos "Prof. Carlos S.A. Segreti”. Universidad Nacional de Córdoba. Corro 308, (5000), Córdoba, Argentina. recaldema@yahoo.com.ar

2 CONICET-División Arqueología, Facultad de Ciencias Naturales y Museo, Universidad Nacional de La Plata. Intersección Av. 60 y 122, (1900), La Plata, Buenos Aires, Argentina. mllopezdepaoli@yahoo.com.ar 
estrategias y patrones de subsistencia flexibles, donde la movilidad estacional desempeñaba un papel central, dado que permitía un uso diversificado del paisaje mediante la explotación de ambientes diferentes y complementarios (pampas de altura y entornos chaqueños) (Recalde 2008-09; Rivero et al. 2010), en tanto proporcionaban diversos recursos a lo largo del año. Así, los calendarios agrícolas no regían la vida de estas comunidades, sino que la agricultura estaba supeditada a la ausencia de otras alternativas al inicio de la estación productiva (Medina et al. 2016).
En tanto, las evidencias arqueobotánicas recuperadas en 16 sitios a cielo abierto trabajados en los últimos 10 años en el área centro-oeste de las Sierras Centrales (Figura 1) (López 2015) permitieron realizar las primeras identificaciones de recursos vegetales. El registro de macro y microrrestos de maíz (Zea mays), zapallo (Cucurbita sp.), porotos (Phaseolus lunatus y P. vulgaris), principalmente aquellos recuperados en áreas de producción y que corresponden a órganos foliares (López 2017; Pastor y López 2011), aportaron datos concretos sobre los recursos cultivados y las estrategias agrícolas. En

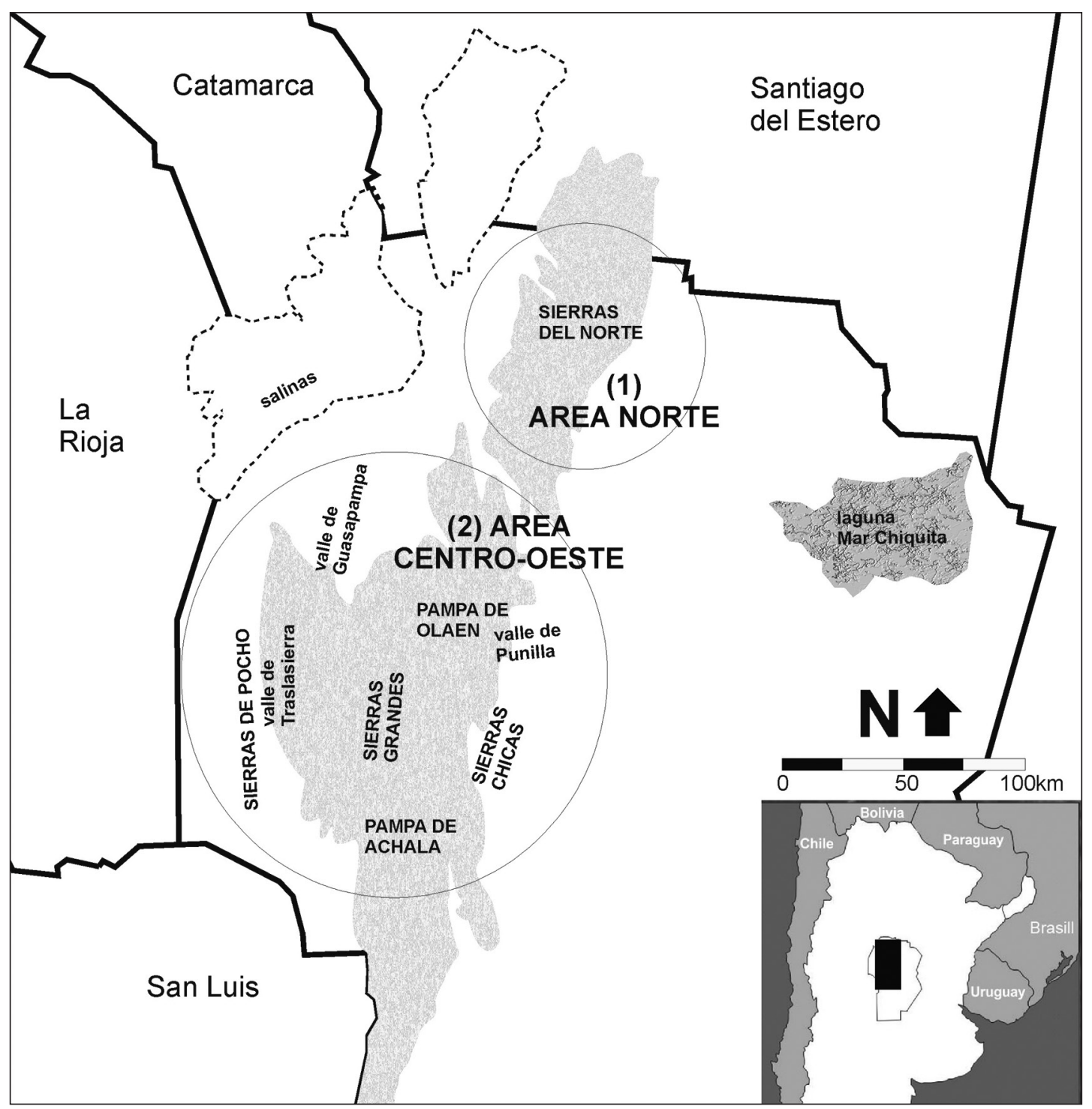

Figura 1. Regiones analizas en las Sierras Centrales: (1) Región Norte, (2) Región Centro-Oeste. Analyzed regions in Sierras Centrales: (1) Northern, (2) Central Western. 
este sentido, la agricultura fue definida como una práctica de policultivos, donde la localización de espacios productivos se vinculada tanto al entorno doméstico como en parcelas dispersas en el paisaje (Pastor y López 2011). Asimismo, se recuperaron microrrestos de Chenopodium spp./Amaranthus spp. en tiestos cerámicos y valores muy elevados de polen de Amaranthaceae (60\%) en los sedimentos que, debido al alto grado de indeterminación, puede ser el resultado tanto de consumo proveniente del cultivo como del impacto generado por disturbio antrópico (López et al. 2014). En tanto, los recursos silvestres permiten dar cuenta de la manipulación de mistol (Sarcomphalus mistol), chañar (Geoffroea decorticans), algarrobo (Prosopis sp. y P. cf. nigra) y poroto silvestre (Phaseolus vulgaris var. aborigineus). Es factible vincular esta última especie con el manejo que implica un continuum silvestre-domesticado, ya que las prácticas productivas prehispánicas pudieron incorporar la explotación de las especies malezoides asociadas a los cultivos (Gremillion 1993; López 2017).

A la luz de estos antecedentes, las evidencias recuperadas en el área septentrional, más precisamente en las Sierras del Norte, permiten marcar similitudes en las estrategias llevadas adelante por los grupos prehispánicos, y al mismo tiempo, destacar especificidades en las prácticas productivas de las sociedades tardías que habitaron este sector durante el PPT. Estos estudios avalarían el planteo de que las comunidades que ocuparon las áreas centrooeste y norte desarrollaron distintas respuestas de subsistencia que involucraban a personas y cultivos en relaciones diversas y dinámicas, de acuerdo a variaciones en la disponibilidad de recursos y factores sociales (i.e. movilidad, lazos y límites territoriales). En este punto, cabe señalar que los documentos hispánicos de los siglos XVI y XVII también indicaban la existencia de una variabilidad subregional en los sistemas productivos de Sierras Centrales. Para el área norte informan sobre el empleo de diferentes estrategias que integraban el cultivo a secano y, a diferencia del área centro-oeste, el empleo de tierras inundables e incluso mencionan la presencia de regadíos (Montes 2008) que, según los sectores, habría favorecido el desarrollo de diferentes asociaciones de plantas domesticadas así como el aprovechamiento de malezas asociadas. No obstante ello, y teniendo en cuenta la subjetividad implícita en los documentos españoles (Bixio y Berberián 2006-2009) que advierten sobre una veracidad relativa de la información consignada, es destacable que si bien hasta el momento no hemos documentado la existencia de canales de riego en la zona objeto de estudio, puede pensarse en sistemas de subsistencia diferenciales entre regiones (considerando que poblaciones nativas actuales englobadas en una misma etnia, ofrecen diferencias en el aspecto económico) (Scarpa 2009).

El objetivo de este trabajo es ofrecer una primera aproximación sobre los recursos vegetales y sus prácticas sociales asociadas desarrolladas por los grupos que habitaron la Sierras del Norte a partir de la información recuperada en tres sitios arqueológicos, con particularidades de ocupaciones distintas, pero complementarias: Quebrada Norte 7 (QN7), Pozancón 1 (Poz1) y Casa del Sol 8 (a) (CS8a) (Figura 2). Los resultados obtenidos del análisis arqueobotánico permiten plantear la existencia de variaciones en el sistema de subsistencia del PPT, relacionado con un posible cambio en las estrategias de movilidad estacional y en consecuencia, la construcción de un vínculo diferente de estas comunidades con la tierra. De la misma manera, el amplio espectro de recursos silvestres registrados y la baja representatividad del algarrobo en la muestra autorizan a repensar la sobrevaloración que se tiene de esta especie como alimento indispensable para la subsistencia prehispánica.

\section{Área de Estudio y Características de los Sitios Arqueológicos}

El sector serrano de la Provincia de Córdoba comprende fitogeográficamente a la provincia Chaqueña-Distrito Chaqueño Serrano o a la ecorregión Chaco Seco-subrregión Chaco Serrano (Hoyos et al. 2012), que se desarrolla entre los 800 y $1.300 \mathrm{msm}$. El tipo de vegetación predominante es el bosque xerófilo caducifolio. Las precipitaciones anuales estivales tienen un promedio anual de 600 $\mathrm{mm}$ y las temperaturas medias son de $17^{\circ} \mathrm{C}$ en verano y $8^{\circ} \mathrm{C}$ en invierno. Los ejemplares arbóreos principales son el mato (Myrcianthes cisplatensis), junto al molle blanco (Sideroxylon obtusifolium) y el ancoche (Vallesia glabra), acompañados por el molle de beber (Lithraea molloides), el coco (Zanthonnxylum coco), el quebracho blanco (Aspidosperma sp.), el aguaribay (Schinus areira), el espinillo (Acacia caven), el piquillín (Condalia buxifolia y C. montana), el chañar, el mistol, algarrobos, entre otros (Zack y Cabido 2002). 


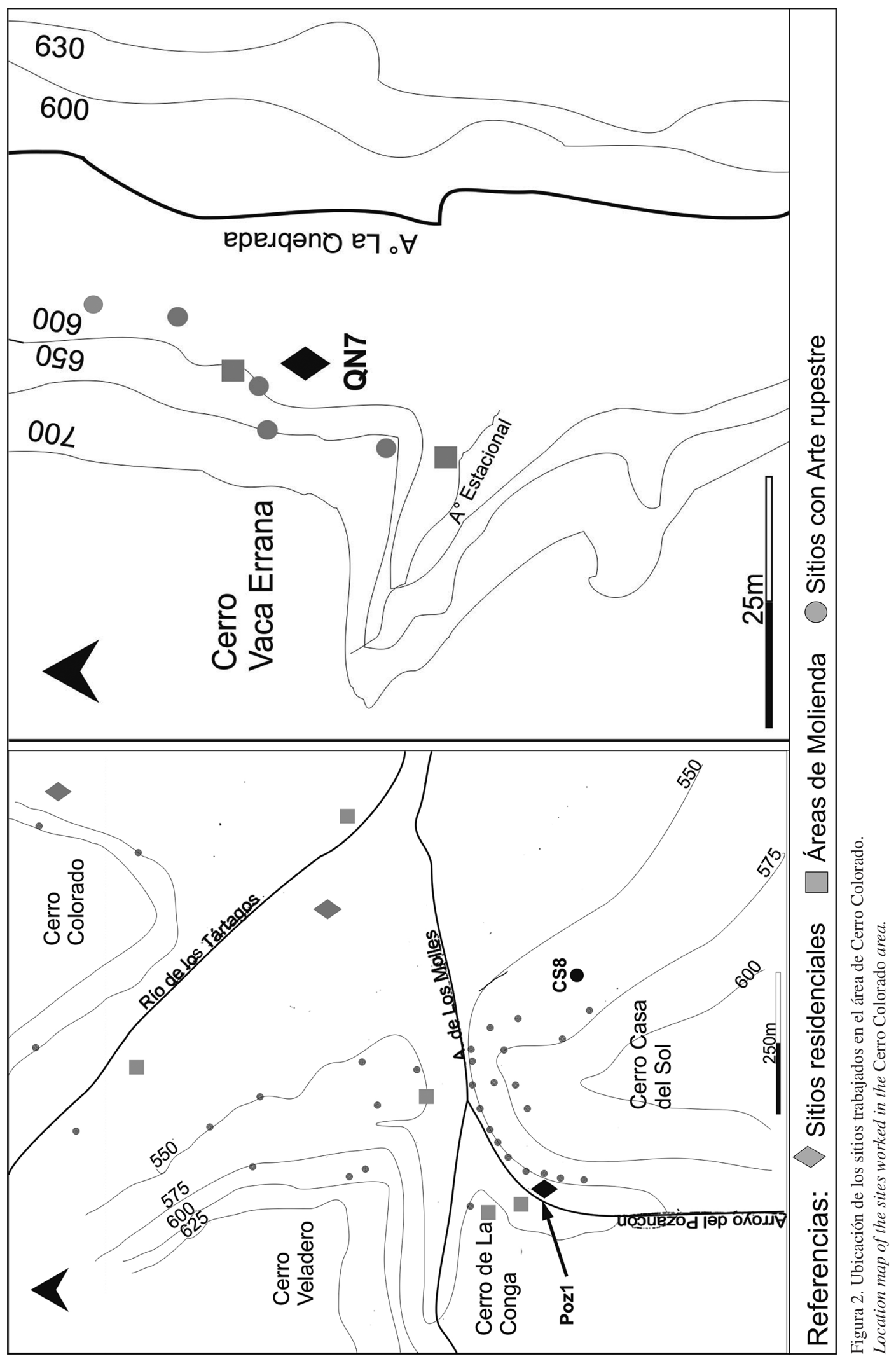


El área arqueológica de Cerro Colorado está ubicada en la vertiente oriental de las Sierras del Norte (Figura 2), formación que se caracteriza por alturas modestas que apenas superan los $1.000 \mathrm{msm}$ y por quebradas transversales que se distribuyen entre las mismas. La cuenca hídrica está conformada por el río de Los Tártagos, en el cual desembocan varios arroyos como La Quebrada y Los Molles, y otros de régimen más intermitente y estacional (Las Trancas y El Pozancón o de las Aguas de Figueroa). Esta buena disponibilidad hídrica permite caracterizarla como un oasis. En una superficie de aproximadamente $40 \mathrm{~km}^{2}$ están distribuidos 48 sitios con arte rupestre, cinco ocupaciones al aire libre y 20 áreas de molienda. Los primeros están emplazados en los sectores bajo y medio de las laderas de las formaciones que integran el área (cerros Casa del Sol, Veladero, Colorado y Vaca Errana) y los otros en las márgenes del río y arroyos que surcan la zona. En este trabajo discutiremos las evidencias macro y microbotánicas recuperadas en tres sitios CS8(a), Poz1 y QN7 (Figuras 2 y 3). En concreto, toda la información recabada da cuenta de una ocupación redundante del entorno muy semejante a la de otros valles de la región centrooeste de Sierras Centrales, que muestran un paisaje de tipo residencial vinculado con la explotación de terrenos potencialmente agrícolas (Medina et al. 2016; Pastor et al. 2012). La diferencia del paisaje de Cerro Colorado es que a este entorno que articulaba diferentes actividades domésticas (vivienda-prácticas productivas) e incluso algunas comunitarias, dada la presencia de tres áreas de molienda que permiten la interacción simultánea de más de 20 personas (ver Babot 2007 y Pastor 2016 para mayor discusión), se articulan los abrigos rocosos con paneles emplazados en los cerros que flanquean los espacios residenciales.
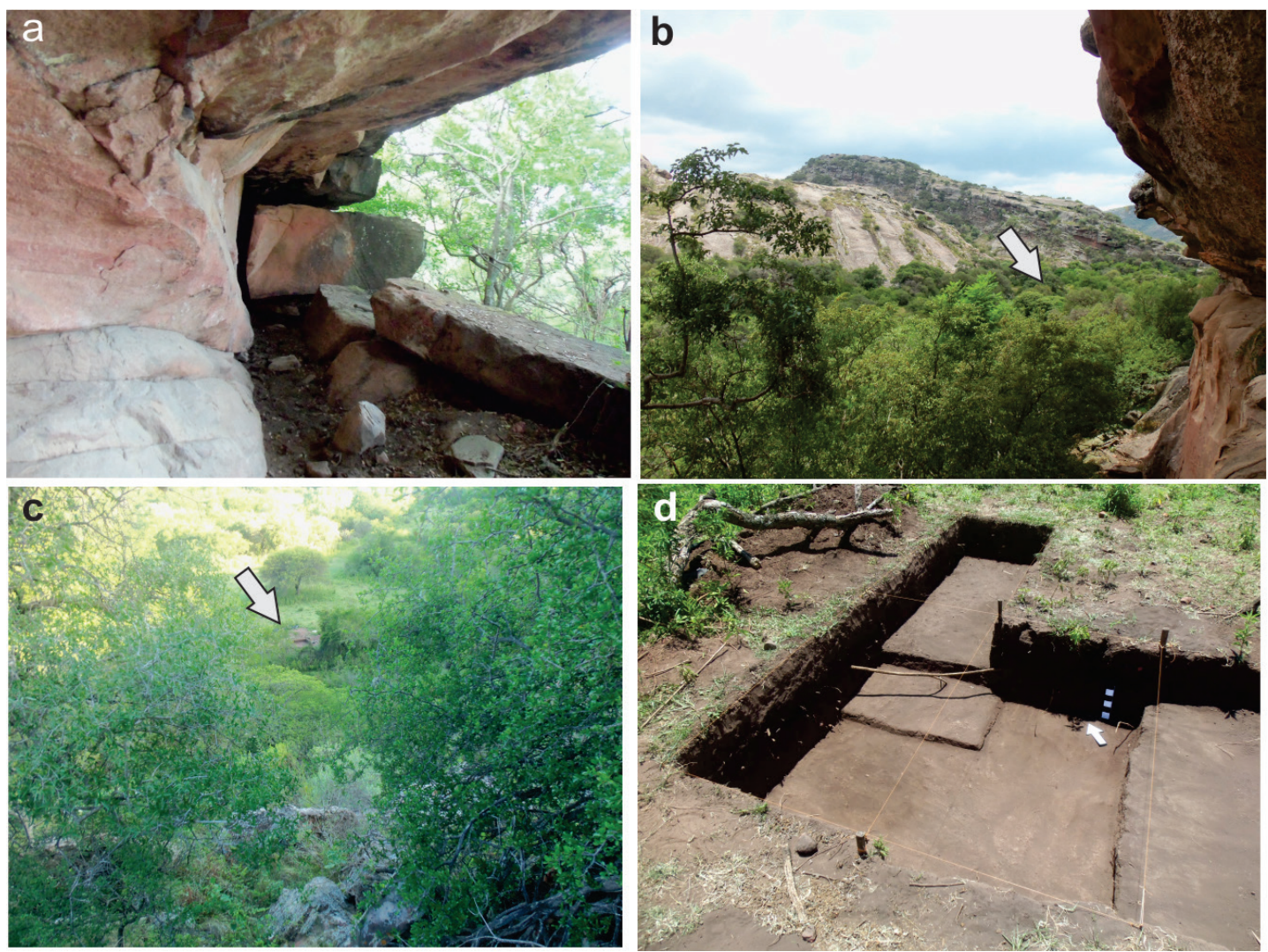

Figura 3. Sitios trabajados: (a) CS8(a); (b) vista del sector en el cual se emplaza Poz1; (c) vista de QN7 en el paisaje de Quebrada Norte; (d) Detalle del área excavada.

Worked Sites: (a) CS8(a); (b) view of sector where Poz1 is located; (c) view of QN7 site in the Quebrada Norte landscape; (d) detail of excavated area. 
El primero de los sitios es un alero o abrigo con representaciones rupestres pintadas ubicado en el sector medio de la ladera este del cerro Casa del Sol (Figura 3a). El área excavada alcanzó los $3 \mathrm{~m}^{2}$ con una potencialidad del depósito que no superó los $0,25 \mathrm{~m}$. Se constató una baja densidad de hallazgos. El tipo de evidencias documentadas consiste en fragmentos cerámicos (total de tiestos $\mathrm{N}=56$ ), que permiten estimar la presencia de vasijas medianas y pequeñas, restos arqueofaunísticos (total de fragmentos $\mathrm{N}=20$ ) que indican un consumo acotado de recursos (Lama sp. y Cavia sp.), y artefactos líticos (total instrumentos $\mathrm{N}=3 \mathrm{y}$ total de desechos de talla $\mathrm{N}=114$ ) vinculados con las instancias finales de formatización y mantenimiento de instrumentos. La conjunción de esta información da cuenta, en general, de la realización de prácticas vinculadas con el procesamiento y consumo de alimentos a pequeña escala, llevadas adelante por un número reducido de individuos, probablemente durante un período limitado de tiempo. En estratigrafía se recuperó una mano de moler correspondiente a una conana o molino plano fragmentada cuya parte activa es de $7 \mathrm{~cm}$ de largo por 9,7 cm de ancho, que fue objeto de estudio arquebotánico. La información ergológica recuperada en CS8(a), es decir cerámica y diseños de instrumentos líticos, permite asignar este sitio al PPT ${ }^{1}$.

Los sitios Poz1 y QN7 fueron caracterizados como espacios residenciales o poblados tardíos prehispánicos, en tanto locus de procesamiento y consumo de alimentos ${ }^{2}$. Pozl está ubicado entre los cerros Casa del Sol y Veladero (Figura 3b), en la margen derecha del arroyo Pozancón o de las Aguas de Figueroa (Recalde 2015). Está asociado a un panel con representaciones pintadas y a un área de molienda conformada por 13 instrumentos fijos (morteros) que se localiza en la margen izquierda del arroyo. Las tareas de sondeos realizadas en el lugar consistieron en la realización de ocho pozos de $0,50 \mathrm{~m} \times 0,50 \mathrm{~m}$, distantes aproximadamente a $10 \mathrm{~m}$, lo que permitió cubrir una superficie de $900 \mathrm{~m}^{2}$. Los datos recabados nos autorizaron a proponer que se trata de una ocupación al aire libre en la que la diversidad de artefactos señala la realización de múltiples actividades. De la misma manera, el registro arqueofaunístico (Lama sp., Cavia sp., Cervidae) indica el acceso a ambientes diferentes al chaqueño en el cual están emplazados los sitios estudiados dado que, por ejemplo, la distribución actual e histórica del guanaco apunta a que se trata de un recurso distante al menos entre $30 \mathrm{~km}$ y $50 \mathrm{~km}$ de la localidad arqueológica de Cerro Colorado $^{3}$. El contexto de hallazgo y los tipos de artefactos recuperados en Poz1 permiten asignar la ocupación al PPT.

Finalmente, QN7 está emplazado en el paraje denominado Quebrada Norte, a unos 6 km de CS8(a) y Poz1. Se ubica en el piedemonte del cerro Vaca Errana y en la margen derecha del arroyo La Quebrada (Figura 3c). Está asociado a cinco aleros rocosos con representaciones pintadas (Colqui 2015; Gardner 1930) y a dos áreas de molienda que cuentan con 21 y 24 instrumentos fijos. El sector intervenido alcanzó los $15 \mathrm{~m}^{2}$, con potencialidad arqueológica hasta los $0,70 \mathrm{~cm}$, en el que documentamos un piso consolidado a $0,45 \mathrm{~m}$. Registramos una alta densidad y concentración estratigráfica de materiales cerámicos (total fragmentos $\mathrm{N}=997$ ), faunísticos (NISP 550), líticos (total desechos de talla $\mathrm{N}=1005$ ) y botánicos (total de macrorrestos carpológicos $\mathrm{N}=441$ ), que al igual que en Poz1, sugieren la realización de múltiples actividades, acordes a una ocupación tipo poblado tardío (Figura 3d). El análisis inicial de la evidencia arqueofaunística también indica el acceso a ambientes diferentes (Cervidae, Lama sp. Cavia sp., Rhea sp., Chaetrophractus villosus) en tanto, como discutiremos más adelante, la información arqueobotánica señala una explotación intensiva del entorno chaqueño circundante a los sitios. Los fechados radiocarbónicos refuerzan la asignación cronológica inicial sugerida para este y los otros sitios residenciales trabajados en el área, dado que ubican la ocupación de QN7 entre el 1250 \pm 80 años a.p. (LP- 3212; carbón) y el $405 \pm 21$ a.p. (AA 107245; grano de maíz), asignación cronológica que se corresponde con el PPT.

\section{Materiales y Métodos}

Durante las excavaciones se aplicaron dos metodologías conjuntas de recuperación de macrorrestos -frutos y semillas: in situ, dispersos en la matriz sedimentaria que contenía todo el material arqueológico- y el cernido de los sedimentos con mallas de 2 y $0,97 \mathrm{~mm}$ de luz. No se aplicó el sistema de flotación debido a que las condiciones de sequedad de la matriz sedimentaria producen una alta fragmentación del material carbonizado. El sedimento cernido fue medido en volúmenes (litros) dando cuenta de 750 litros en el sitio CS8, 2.000 litros en el sitio Poz1 y 6.000 litros en 
QN7. No obstante, solo el sitio QN7 proporcionó especímenes carpológicos carbonizados, algunos parcialmente deteriorados (Tabla 1). Consideramos que la ausencia de restos botánicos en Poz1 y CS8 puede deberse, por un lado, a la no preservación de los restos, ya que si no han entrado en contacto con el fuego, las condiciones ambientales no permiten su conservación en el tiempo, y por otro lado, a la ocupación a pequeña escala que incide en la densidad de restos botánicos que pueden ser desechados.

Todos los ejemplares fueron escaneados en su totalidad bajo microscopio esteroscópico de hasta 100X para su clasificación y descripción. Se tuvieron en cuenta los caracteres cualitativos (morfología, rasgos en superficie, entre otros) y cuantitativos (largo, ancho, espesor, y diámetro en el caso que correspondiese). Para su identificación se empleó material actual de las colecciones de referencia depositados en el laboratorio 129 de la División de Arqueología (Unidad Anexa al Museo, FCNyM, UNLP), atlas de ilustración de semillas y bibliografía específica, tanto de material actual, como de restos arqueológicos (Capparelli 2011; López et al. 2015; Oliszewski 2008; entre otros).

El análisis arqueobotánico se basó en determinar la Ubicuidad y la Densidad. La Ubicuidad se refiere a determinar la presencia/ausencia de un taxón por la frecuencia de aparición mediante la medición del número de muestras en las que se identificó dicho taxón. La Densidad se corresponde con la cantidad absoluta de cada taxón por litro de sedimento y los gramos de cada taxón por litro de sedimento, lo que permite evaluar la importancia relativa de cada uno dentro de cada muestra (Hastorf y Popper 1988). Dado el gran volumen de sedimento cernido las densidades se expresarán cada 10 litros.

El análisis de silicofitolitos y granos de almidón se aplicó a tiestos cerámicos e instrumentos líticos de molienda recuperados en Poz1 y CS8(a), debido a la ausencia de macrorrestos carpológicos en estos sitios. El procedimiento que se llevó a cabo se corresponde con el raspado directo y en seco con un instrumento punzante de acero sobre las diferentes superficies. En los fragmentos cerámicos se realizó sobre la pared interna, a modo de registrar qué especie/s estuvo/vieron involucrada/s en las etapas principalmente de cocción. En tanto, para el instrumento lítico de molienda, se efectuó sobre las áreas activas y pasivas, priorizando grietas y oquedades, para registrar recursos procesados. $\mathrm{La}$ metodología empleada sigue los parámetros estándar establecidos para el trabajo arqueobotánico en microrrestos (Pearsall 2015; Perry 2004; Piperno 2006; entre otros) Tanto el área de trabajo como el instrumental empleado fueron esterilizados a fin de evitar posibles contaminaciones. El montado en

Tabla 1. Macrorrestos botánicos identificados en Quebrada Norte 7. Número total de macrorrestos $=441$ carporrestos. Número total muestras $=28$ muestras.

Total sedimento cernido $=6.000$ litros de sedimento.

Botanical macro-remains identified at Quebrada Norte 7.

Total number of macro-remains $=441$. Total number of samples analyzed $=28$. Total sifted sediment $=6,000$ litres.

\begin{tabular}{lcccccc}
\hline \multicolumn{1}{c}{ Taxa } & $\begin{array}{c}\mathrm{N}^{\circ} \mathrm{de} \\
\text { muestras }\end{array}$ & $\begin{array}{c}\text { Ubicuidad } \\
(\%)\end{array}$ & $\begin{array}{c}\text { Cantidad } \\
\text { absoluta }\end{array}$ & $\begin{array}{c}\text { Peso } \\
(\mathrm{gr})\end{array}$ & $\begin{array}{c}\text { Densidad } \\
(\mathrm{CA} / 10 \\
\text { litros })\end{array}$ & $\begin{array}{c}\text { Densidad } \\
(\text { Peso/10 } \\
\text { litros })\end{array}$ \\
\hline Sarcomphalus mistol & 13 & 46,43 & 65 & 15,59 & 0,11 & 0,026 \\
Lithraea molloides & 13 & 46,43 & 258 & 7,52 & 0,43 & 0,013 \\
Zea mays & 7 & 25 & 10 & 0,13 & 0,02 & 0,0002 \\
Condalia sp. & 8 & 28,57 & 16 & 1,36 & 0,03 & 0,0023 \\
Prosopis sp. & 5 & 17,86 & 27 & 2,23 & 0,05 & 0,004 \\
Schinus cf. areira & 4 & 14,28 & 12 & 0,19 & 0,02 & 0,0003 \\
Geoffroea decorticans & 1 & 3,57 & 1 & 0,02 & 0,002 & 0,00003 \\
Phaseolus sp. & 1 & 3,57 & 1 & 0,01 & 0,002 & 0,00001 \\
Chenopodium quinoa var. quinoa & 1 & 3,57 & 1 & 0 & 0,002 & 0 \\
Chenopodium quinoa cf. var. melanospermum & 1 & 3,57 & 2 & 0 & 0,003 & 0 \\
Cf. Amaranthus sp. & 1 & 3,57 & 1 & 0 & 0,002 & 0 \\
Leguminoseae & 1 & 3,57 & 1 & 0 & 0,002 & 0 \\
No identificadas & 11 & 39,28 & 46 & 2,3 & 0,08 & 0,004 \\
\hline
\end{tabular}


aceite de inmersión sobre portaobjeto fue directo y el escaneado se realizó en microscopio óptico de luz transmitida y en campo polarizado con aumento de 500X.

Los silicofitolitos fueron descritos morfométricamente y clasificados siguiendo el Código Internacional de Nomenclatura Fitolítica (ICPNMadella et al. 2005) y material bibliográfico (Fernández Pepi 2013; Pearsall 2015; Twiss et al. 1969; entre otros). Se fotografió y se estableció el origen anatómico de fitolitos posibles de identificar.

Los granos de almidón fueron observados y descritos siguiendo la morfología tridimensional, el tamaño del grano, los rasgos de contorno y superficie, la forma y el tamaño del hilum, la visibilidad de la lamella, la presencia de fisuras, las propiedades de bi-refringencia, el rasgo de la cruz de extinción y la visibilidad del grano en luz normal y en campo polarizado (Babot 2004; Perry 2004; Piperno y Holst 1998).

Para la identificación, tanto de fitolitos como de almidones, se recurrió a muestras comparativas propias, tanto de muestras actuales, como arqueológicas y a bibliografía específica (Cortella y Pochettino 1995; Giovanetti et al. 2008; Korstanje y Babot 2007; Piperno 2006; entre otras).

\section{Resultados}

En CS8(a) y Poz1, como mencionamos anteriormente, no se recuperaron carporrestos, por lo tanto fueron analizados microrrestos, tanto silicofitolitos como almidones procedentes de contextos particulares. De la mano de moler hallada en CS8(a) se determinaron silicofitolitos afines a la mazorca de maíz (morfotipo cónico truncado de base plana y ápice ondulado -wavy-top rondel) (Figura 4a) y un grano de almidón que no presenta características diagnósticas. En Poz1 se recuperaron fragmentos cerámicos, correspondientes al cuerpo de las vasijas, y se obtuvieron fitolitos diagnósticos de hojas de Poaceae, también presentes en la matriz sedimentaria, y granos de almidón de órganos subterráneos (tubérculos y raíces tuberosas), cuyas características son afines a cf. Solanum sp. (posible papa cultivada) (almidones simples ovalados con hilo excéntrico, con lamellas poco visibles. Su cruz de polarizado es excéntrica de brazos finos, dos largos y dos cortos) (Figura 4b-c) y afines a cf. Ipomoea batata (batata o camote) o cf. Manihot sp. (mandioca) (almidones simples en forma de campana, con hilum céntrico en forma de punto y lago fisurados. La cruz de polarización es céntrica con brazos finos y dos parecen ser de forma cóncava) (Figura 4d-e). En este último caso, los rasgos observables no permiten la diferenciación entre ambos géneros, lo que impide determinar si pertenecen a mandioca o a batata.

En QN7, se recuperó un total de 441 carporrestos en los 6.000 litros de sedimento cernidos (si bien algunos fueron extraídos in situ, son considerados dentro del volumen cernido por ser una actividad conjunta). El 90\% del material pudo ser incluido en una categoría taxonómica, mientras que el $10 \%$ corresponde a semillas y endocarpos aún no categorizados. Se identificó mistol, chañar, maíz, poroto, molle de beber, piquillín (Condalia sp.), algarrobo (Prosopis sp.), aguaribay (Schinus cf. areira), quinoa (Chenopodium quinoa $\mathrm{cf}$. var. quinoa), ajara (C. quinoa var. melanospermum), amaranto (cf. Amaranthus sp.) y Leguminosae (Figura 5, Tabla 1).

Se observa una elevada presencia de especies, que incluye tanto recursos silvestres distribuidos en el ambiente como domesticados, cuya producción en la región permitió la incorporación de malezas. Se advierte también que no hay una distribución homogénea de los individuos por especie, ya que las taxa silvestres son las que dominan la asociación arqueobotánica. El molle y el mistol están representados con una alta frecuencia de individuos en el total de las muestras analizadas y el maíz tiene una leve representación (Tabla 1; ver López 2017 para mayor información). Es importante aclarar que tanto el mistol como el molle tienen ejemplares que contienen signos de almacenamiento o de guardado prolongado, es decir, no solo se corresponden con endocarpos limpios sino también con frutos enteros con rasgos de haber sido secados (mistol) y de endocarpos con mesocarpo adheridos y orificio de gusano típico de ataque de plagas posiblemente tras el almacenamiento (molle) (Figura $5 \mathrm{a} \mathrm{y} \mathrm{b).}$

\section{Discusión de las Evidencias}

Los grupos de la región centro-oeste durante el PPT se caracterizaron por un patrón de explotación y asentamiento flexible, estrategia orientada a una ocupación estacional de los ambientes. En este contexto la agricultura fue incorporada como práctica económica que se integró a un proceso de intensificación del consumo de recursos iniciado 


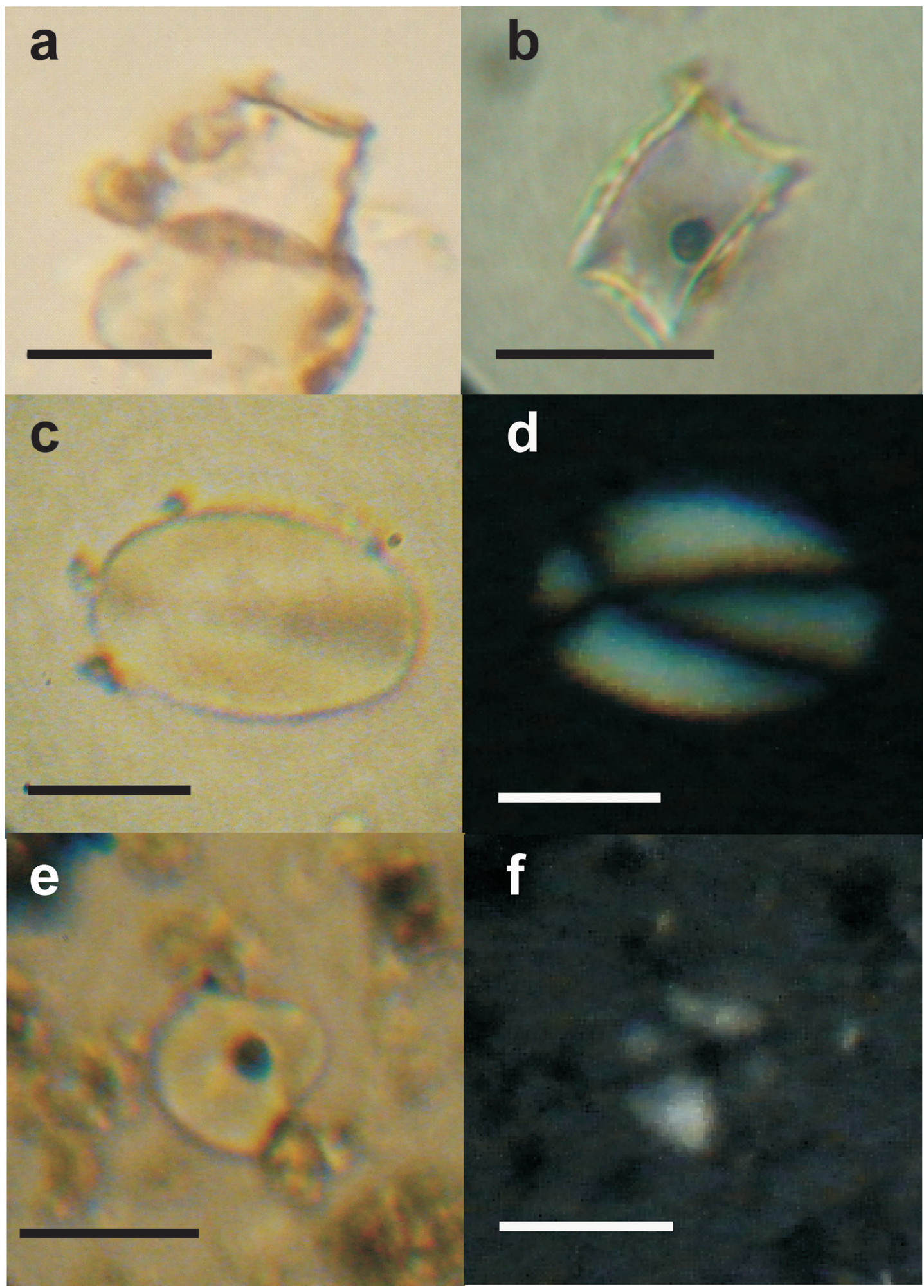

Figura 4. (a) fitolitos arqueológico de Zea mays fragmentado; (b) fitolito actual de Zea mays; (c-d) Almidón aff. a Solanum sp.; (e-f) Almidón afín a Ipomea sp. o Manihot sp. E=20 $\mu \mathrm{m}$.

(a) broken archaeological phytolith of Zea mays; (b) modern phytolith of Zea mays; $(c-d)$ starch grain of $c f$. Solanum $s p$.; (e-f) starch grain of cf. Manihot sp. or Ipomea sp. Scale bar=20um. 

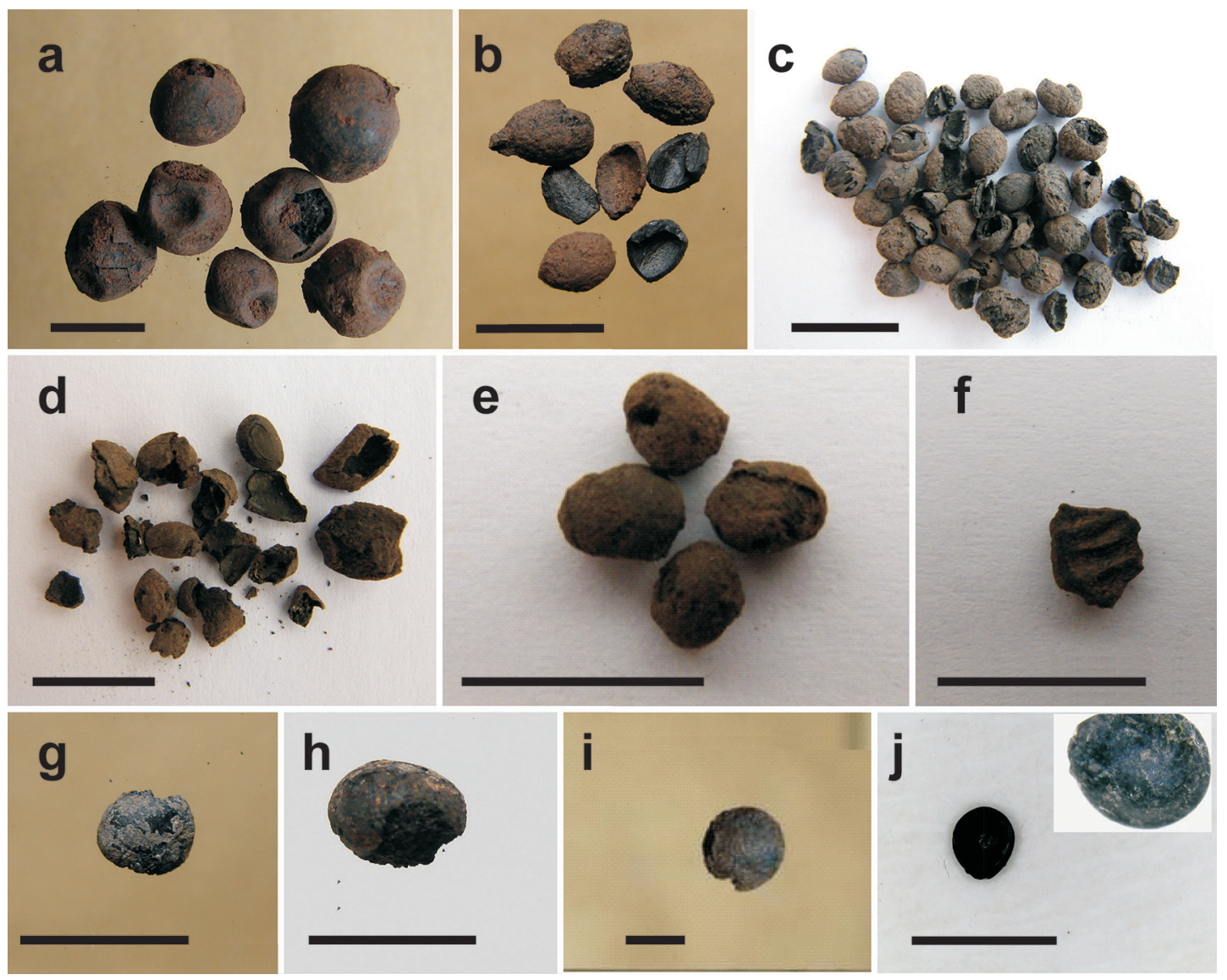

Figura 5. Macrorrestos botánicos recuperados en los sitios QN7, Poz1 y CS8(a). (a-b) Sarcomphalus mistol: (a) frutos enteros; (b) endocarpos. (c) frutos de Lithraea molloides; (d) endocarpos y semillas de Prosopis sp.; (e) semillas de Schinus cf. areira; (f) endocarpo de Geoffroea decorticans; (g) grano (ápice) de Zea mays; (h) cotiledón de Phaseolus sp.; (i) grano de Chenopodium quinoa var. quinoa; (j) granos de cf. Amaranthus sp. y su imagen ampliada. E (k-m)=20 $\mu \mathrm{m}$. E (a-h)=10mm; E (i-j)=2 mm. Botanical macro-remains at Cerro Colorado. (a) fruits of Sarcomphalus mistol; (b) endocarps of Sarcomphalus mistol; (c) fruits and endocarps of Lithraea molloides; $(d)$ seeds and endocarps of Prosopis sp.; $(e)$ endocarps of Schinus $c f$. areira; $(f)$ endocarp of Geoffroea decorticans; $(g)$ kernel of Zea mays; $(h)$ cotyledon of Phaseolus sp.; $(i)$ grain of Chenopodium quinoa var. quinoa; (j) seed of Amaranthus sp. Scale bar $(a-h)=10 \mathrm{~mm}$. Scale bar $(i-j)=2 \mathrm{~mm}$.

hacia el Holoceno Medio-Tardío (4000-3000 a.p.), la cual estaba supeditada a la recolección, dado que era interrumpida cuando los recursos silvestres de mayor rendimiento estaban disponibles en otras áreas, por ejemplo los paisajes occidentales (Medina et al. 2016). No obstante, este modelo no debe ser considerado de manera rígida y extendido a toda la región de Sierras Centrales. La evidencia arqueobotánica recuperada en el área septentrional permite, por un lado replantear algunas nociones que fueron asumidas a priori (p.ej. la importancia del algarrobo) y por otro, comenzar a incorporar datos a la problemática que indican el desarrollo de distintas prácticas y estrategias llevadas adelante por los grupos que ocuparon el área de Cerro Colorado. Estas probablemente fueron generadas por las características y ofertas ambientales diferentes y por las decisiones culturales.

Los recursos vegetales comestibles recuperados en CS8(a), Poz1 y QN7 indican una gran diversidad de taxa tanto silvestre como doméstica y malezoides (Tabla 2). La evidencia reunida da cuenta así que los grupos incorporaron a la subsistencia aquellas especies que el ambiente ofrece en las áreas ubicadas en las inmediaciones de los sitios como así también aquellas cuya producción es posible en la región. No obstante, se refleja en cierto modo que los recursos silvestres se constituyen en el principal 
Tabla 2. Presencia diferencial de evidencia arqueobotánica (macro y microrrestos) en las regiones Norte y Centro-Oeste de la provincia de Córdoba.

Differential presence of archaeobotanical evidence (macro and micro-remains) in the northern and central-western regions of Córdoba province.

\begin{tabular}{|c|c|c|c|c|}
\hline \multirow{2}{*}{ Región } & \multirow{2}{*}{ Sitio } & \multirow{2}{*}{ Cronología } & \multicolumn{2}{|c|}{ Dato arqueobotánico } \\
\hline & & & Macrorrestos & Microrrestos \\
\hline \multirow[t]{3}{*}{ 䒕 } & QN7 & $\begin{array}{l}1250 \pm 80 \text { a.p. (LP-3212) } \\
405 \pm 21 \text { a.p. (AA107245) }\end{array}$ & $\begin{array}{l}\text { Sarcomphalus mistol } \\
\text { Lithraea molloides } \\
\text { Condalia } \text { sp. } \\
\text { Prosopis sp. } \\
\text { Schinus cf. areira } \\
\text { Zea mays } \\
\text { Phaseolus sp. } \\
\text { Chenopodium quinoa var. quinoa } \\
\text { Chenopodium quinoa } \text { cf. var. } \\
\text { melanospermum } \\
\text { cf. Amaranthus sp. }\end{array}$ & \\
\hline & Poz1 & Período Prehispánico Tardío & & $\begin{array}{l}\text { Solanum cf. tuberosum } \\
\text { cf. Ipomea / cf. Manihot }\end{array}$ \\
\hline & CS8(a) & Período Prehispánico Tardío & 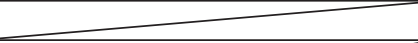 & Zea mays \\
\hline \multirow{11}{*}{$\begin{array}{l}0 \\
\frac{0}{02} \\
0 \\
1 \\
0 \\
0 \\
0 \\
0\end{array}$} & QR1 & $\begin{array}{l}5980 \pm 50 \text { a.p. (LP-2133) } \\
2950 \pm 90 \text { a.p. (LP-2042) }\end{array}$ & & $\begin{array}{l}\text { Chenopodium sp. } \\
\text { Zea mays }\end{array}$ \\
\hline & CCh3 & $2466 \pm 51$ a.p. (AA68146) & & Zea mays \\
\hline & YP1 & $1360 \pm 60$ a.p. (LP-1812) & & $\begin{array}{l}\text { Cf. Prosopis sp. } \\
\text { Zea mays }\end{array}$ \\
\hline & CCP3 & $390 \pm 60$ a.p. (LP-1709) & 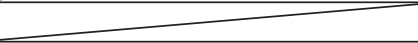 & Cf. Prosopis sp. \\
\hline & PE1 & $\begin{array}{l}365 \pm 38 \text { a.p. (AA64816) } \\
362 \pm 43 \text { a.p. (AA64815) }\end{array}$ & $\begin{array}{l}\text { Zea mays } \\
\text { Phaseolus vulgaris var. vulgaris } \\
\text { Phaseolus vulgaris var. aborigineus } \\
\text { Phaseolus lunatus }\end{array}$ & Zea mays \\
\hline & C.Pun.39 & $\begin{array}{l}854 \pm 39 \text { a.p. (AA62338) } \\
716 \pm 39 \text { a.p. (AA62339) } \\
525 \pm 36 \text { a.p. (AA64819) }\end{array}$ & $\begin{array}{l}\text { Prosopis } \mathrm{sp} . \\
\text { Zea mays } \\
\text { Phaseolus vulgaris } \\
\text { Phaseolus lunatus } \\
\end{array}$ & $\begin{array}{l}\text { Chenopodium sp./Amaranthus sp. } \\
\text { Cucurbita } \mathrm{sp} .\end{array}$ \\
\hline & AT2 & $\begin{array}{l}980 \pm 60 \text { a.p. }(\text { LP-2262)/ } \\
740 \pm 60 \text { a.p. (LP-1450) }\end{array}$ & cf. Lithraea molloides & \\
\hline & ATC1 & $\begin{array}{l}1028 \pm 40 \text { a.p. (AA64820) } \\
900 \pm 70 \text { a.p. (LP-1511) }\end{array}$ & $\begin{array}{l}\text { Phaseolus vulgaris } \\
\text { Phaseolus lunatus }\end{array}$ & $\begin{array}{l}\text { Cucurbita sp. } \\
\text { Zea mays }\end{array}$ \\
\hline & BP2 & $\begin{array}{l}750 \pm 70 \text { a.p. } \\
1060 \pm 50 \text { a.p. } \\
1500 \pm 80 \text { a.p. }\end{array}$ & $\begin{array}{l}\text { Sarcomphalus mistol } \\
\text { Zea mays } \\
\text { Phaseolus vulgaris } \\
\text { Prosopis sp. }\end{array}$ & \\
\hline & RY11 & $\begin{array}{l}1540 \pm 50 \text { a.p. (LP-1658) } \\
1170 \pm 50 \text { a.p. (LP-1449) }\end{array}$ & Sarcomphalus mistol & \\
\hline & RY14 & $640 \pm 70$ a.p. (LP-1514) & Sarcomphalus mistol & \\
\hline
\end{tabular}

aporte alimenticio. Esto entra en concordancia con las características planteadas para las sociedades tardías, donde las prácticas extractivas tuvieron un papel preponderante (Medina et al. 2016).

Las investigaciones que se están llevando adelante en el área septentrional permiten proponer como hipótesis un desarrollo similar de la práctica productiva del sector centro-oeste de las sierras de Córdoba, es decir una agricultura a pequeña escala y de baja tecnificación (Pastor y López 2011). Sin embargo, QN7, CS8 y Poz1ofrecen un panorama agrícola con algunas diferencias. En primer lugar, se evidencia una mayor riqueza de especies que estuvieron bajo producción, ya que no solo están presentes el maíz y el poroto como en los otros sitios arqueológicos de Córdoba (López 2015, 2016) (Tabla 2), sino que también se registra por primera vez la quinoa junto a su maleza -quinoa negra o ajara 
(López y Recalde 2016), y órganos subterráneos tuberosos como la papa y la batata o mandioca. Tal como se mencionó anteriormente, no es claro si los almidones se corresponden con batata o con mandioca, al igual que tampoco podemos aseverar si los almidones serían de especies cultivadas o silvestres de Ipomea. Por tal motivo, hasta no lograr una mejor identificación no haremos hincapié en lo que representaría el género en sí mismo sino en la importancia de la presencia de órganos subterráneos de plantas dentro de la alimentación prehispánica.

Ante el registro arqueobotánico expuesto, podemos plantear la existencia de diferentes estrategias implementadas respecto al sistema agrícola del área centro-oeste de la provincia. En este sentido, estudios paleoambientales aportan datos concretos sobre la persistencia de las mismas condiciones ambientales durante los últimos 1.000 años (Piovano et al. 2009). Esta situación autoriza a proponer que la papa pudo cultivarse en los mismos calendarios productivos que en la actualidad, es decir en un ciclo semitemprano, que se siembra en julio-agosto, y la tardía, que se siembra en febrero y se cosecha en junio-julio (Bouzo 2009; Huarte y Capezio 2015), lo que pudo dar lugar a una relación de las sociedades prehispánicas con las parcelas de cultivo que debió iniciarse en períodos invernales. Es posible así que los ciclos de la papa generaran un patrón diferente respecto a las estrategias de asentamiento flexibles planteadas para el sector centro-oeste, a través de la construcción de un vínculo distinto con la tierra, dado que al incorporar este cultivo los calendarios agrícolas debieron ser diferentes. Por el momento, este planteo requiere de mayor evidencia y que será puesto a prueba con el incremento del trabajo de campo y laboratorio, pero es oportuno aclarar que esta propuesta no implica una vuelta a un sedentarismo entendido en términos tradicionales, sino que el objetivo es proporcionar líneas que permitan dar cuenta de las diferentes respuestas por parte de los grupos prehispánicos en ambientes específicos, frente a requerimientos culturales únicos y en tiempos históricos particulares, o en otros términos aportar a la comprensión de que las prácticas productivas son parte de un proceso dinámico donde la creatividad y las distintas soluciones son estrategias centrales ante circunstancias cambiantes (Korstanje 2015:26).

La inclusión del complejo andino de quenopodiáceas es otra importante evidencia, de la cual solo se tenía referencia en los documentos españoles y los registros de microrrestos sin adscripción específica (López et al. 2014). En la adopción de prácticas de producción desde el 800 d.C. (Pastor et al. 2012) fue incorporado el complejo cultivo/maleza de Chenopodium quinoa, tal como se identificó en sitios arqueológicos del NOA y COA (Lagiglia 2005; Ratto et al. 2014). El consumo de quenopodios silvestres cuenta con evidencias desde el 3000 a.p. y, por ende, los conocimientos previos referidos a las técnicas de cosecha y procesamiento post-cosecha para que estas semillas puedan ingerirse (i.e. la desaponización) pudo favorecer la incorporación de la quinoa entre los recursos alimenticios (López et al. 2014; López y Recalde 2016). Se debe aclarar que este sistema productivo donde se practica la tolerancia y/o incentivo de la denominada maleza en la parcela de cultivo, posiblemente fue implementado en la región centro-oeste de las sierras de Córdoba por la presencia de Phaseolus vulgaris var. aborigineus, aunque esta especie también crece fuera de los campos agrícolas.

Con respecto a los recursos silvestres, el mistol se presenta en gran cantidad con respecto a otros sitios (López 2017), respondiendo a un patrón que comienza a revelarse como común para toda la provincia. Sitios arqueológicos de la región centrooeste con características de ocupaciones domésticas y extradomésticas, dan cuenta del consumo de esta especie (López 2015, 2017). Asimismo, los rasgos de almacenamiento reconocidos en el mistol recuperado en QN7 revelan, por primera vez, esta práctica en la provincia para tiempos prehispánicos (i.e. secado), la cual se ha referenciado solo en la bibliografía etnohistórica y etnobotánica (Trillo 2010), pero principalmente para el algarrobo (Arias Toledo 2008; Berberián 1987).

$\mathrm{El}$ algarrobo merece un apartado especial, dado que los restos recuperados en QN7 son escasos comparados con los otros recursos silvestres, lo que lleva a preguntarnos si efectivamente constituyó un recurso alimentario primordial como ha sido considerado hasta el momento. En la región centrooeste este fruto solo posee evidencias certeras de su consumo en dos sitios arqueológicos (López $2015,2017)$, y otro en el que no está confirmado su taxón específico (Laguens 1999). Frente a este panorama, los carporrestos de Prosopis recuperados en QN7 son los más abundantes para toda la región de Sierras Centrales. Al respecto, resulta factible pensar en una posible sobreestima de este recurso, la cual puede deberse a influencias externas más 
que a la realidad prehispánica (ver López 2017 para una mayor discusión del tema). En primer lugar, se considera que la alta presencia de macrorrestos de algarrobo en numerosos sitios del NOA (Capparelli y Lema 2011; Giovannetti et al. 2008; Oliszewski 1999) pudo influir en considerarlo como básico para la subsistencia en la región Centro. Paralelamente, la información etnobotánica obtenida a lo largo del NOA, NEA y COA refuerza el papel del algarrobo como un alimento tradicional y con raigambre de marcada profundidad (Capparelli 2007; Sciammaro 2015). En segundo lugar, los documentos españoles de los siglos XVI y XVII dieron cuenta de una colecta anual, almacenamiento y consumo no solo en tiempos de escasez de alimentos, sino también como ingesta a modo de bebida fermentada en los momentos de agregación y reproducción sociopolítica (Berberián 1987; Castro Olañeta 2004). Estas perspectivas pudieron llevar a una ponderación del papel del algarrobo en la región de Sierras Centrales. No es nuestro objetivo negar el consumo de esta especie ni su alta versatilidad en las formas de procesamiento (Capparelli 2007), que la convierte en un recurso altamente seleccionable, pero sí ponemos en duda el rol predominante que le fue otorgado como alimento por sobre el resto de los recursos vegetales chaqueños. Esta propuesta se respalda en que esta sobrevaloración no se condice con el registro arqueobotánico por su escasez ni con los datos etnobotánicos y botánicos propiamente dichos. La información etnobotánica indica que, aunque el algarrobo tiene un papel significativo en el imaginario popular (los pobladores de los ambientes chaqueños lo denomina "Padre" o "Árbol") (Arias Toledo 2008: 42), su aporte esencial a las economías campesinas se da en torno a su uso como forraje en épocas de sequía, que a su vez está supeditado a las condiciones ambientales. Por otro lado, la abundancia de precipitaciones afecta las condiciones de fructificación y anula su disponibilidad, como también es factible la fructificación diferencial entre los individuos de una misma población y de año a año (Arias Toledo 2008, 2009; Trillo et al. 2010; Villagra et al. 2004).

En QN7 se han registrado recursos silvestres que no presentan antecedentes arqueológicos en los sitios de la región centro-oeste de Sierras Centrales, que son piquillín, molle y aguaribay. En regiones cercanas a la estudiada, solo el primero fue reconocido en el contexto arqueológico de los grupos cazadores-recolectores del sur de Mendoza
(Llano 2014). El molle es mencionado en los documentos españoles del siglo XVI (Berberián 1987) en tanto la información etnobotánica indica el manejo del aguaribay y del piquillín solo como plantas medicinales y como tintóreas, tanto para la región centro-oeste y norte de Córdoba como para el área centro y sur de Santiago del Estero (Arias Toledo 2010; Riat 2012; Trillo y Demaio 2007). Estas evidencias permiten comenzar a delimitar la vinculación que los grupos prehispánicos de la región norte tenían con los paisajes serranos, donde el espacio productivo claramente no estaba limitado al entorno doméstico inmediato, sino que se incluyeron aquellas especies que, sin ser domesticadas, participaban cotidianamente de la reproducción de los grupos (p.ej. Johnston 2005; Lema 2013).

\section{Consideraciones Finales}

Los recursos identificados en el área septentrional de Sierras Centrales dan cuenta de una amplia variedad de especies vegetales antes no registradas en la región centro-oeste, concordante con el proceso de diversificación e intensificación en el consumo de plantas planteado para el centro de Argentina, que se inició en el ca. 3000 a.p. y que se extendió hasta la llegada de los españoles. Así, en las Sierras del Norte se individualizaron especies silvestres, domesticadas y malezoides, algunas sobre las que no se tenía conocimiento directo como el molle de beber o el aguaribay. En tanto la presencia de otros recursos permite reposicionar y reordenar su relevancia en la subsistencia, como el algarrobo que no puede ser considerado como un recurso central, mientras que el mistol comienza a ganar relevancia en todo el sector serrano de la provincia de Córdoba, con claras evidencias de almacenamiento.

Las prácticas agrícolas desarrolladas en la región norte dan cuenta de grandes similitudes con las estrategias del sector centro-oeste en torno al desarrollo de una agricultura de pequeña escala, en tanto involucró superficies potencialmente cultivadas reducidas, con una baja tecnificación, por ejemplo la ausencia de sistemas de riego y sin muros de contención, que generó una escasa modificación del paisaje a corto plazo, en tanto las estrategias usadas se vincularían con una agricultura de limpieza del terreno y siembra directa (ver Medina et al. 2017 para discusión sobre evidencias de modificación de paisaje por movilidad y reocupación de sitio). 
No obstante, uno de los puntos de divergencia se centra en que los entornos de explotación estacional, lejos de presentarse como desarticulados de los productivos, estaban claramente integrados. En suma, el espacio productivo incluía no solo el ámbito domesticado asociado a la chacra sino el paisaje silvestre, situación que es común entre muchos de los campesinos serranos actuales, quienes denominan como "plantas de la casa" a aquellas especies silvestres que crecen en las áreas cercanas al hogar (Arias Toledo 2008:40; Trillo 2016).

Las apreciaciones y propuestas son aún preliminares y requieren del incremento del número de sitios y de evidencia. Sin embargo, estos primeros avances están proporcionando valiosa información para comenzar a comprender la complejidad de las decisiones y elecciones por parte de los grupos que habitaron el sector septentrional (y el sector serrano en general) durante el PPT. A futuro, el objetivo es indagar sobre los procesos de selección de los recursos chaqueños que se incluyen en la subsistencia y que presentaron una significación cognitiva y simbólica ya que, en última instancia, constituyen el marco para la elección y el manejo intensivo o no de una determinada planta.

Agradecimientos: el presente trabajo se integra a proyectos que han recibido subsidios de CONICET (PIP $11220120100381 C$ y $2014-2016$ GI), SECYT (30720150100747CB) y del Programa de Incentivos UNLP, Ref. 11/N734. Deseamos agradecer a Cecilia Trillo la lectura crítica realizada a una versión anterior del manuscrito. También a Erica Colqui, Valentina Saur Palmieri, Luis Tissera y Juan Montegú que compartieron las tareas de campo. Finalmente al aporte de las/los evaluadores que ayudaron a mejorar el trabajo.

\section{Referencias Citadas}

Arias Toledo, B. 2008. Uso de Plantas Alimenticias y Medicinales en Córdoba. Fitogeografía y Cultura. Tesis para optar al grado de doctor en ciencias biológicas, Facultad de Ciencias Exactas Físicas y Naturales, Universidad Nacional de Córdoba, Córdoba.

Arias Toledo, B. 2009. Diversidad de usos, prácticas de recolección y diferencias según género y edad en el uso de plantas medicinales en Córdoba, Argentina. Boletín Latinoamericano y del Caribe de Plantas Medicinales y Aromáticas 8:389-401.

Babot, M.P. 2004. Tecnología y Utilización de Artefactos de Molienda en el Noroeste Prehispánico. Tesis para optar al grado de doctor en Arqueología. Facultad de Ciencias Naturales e I.M.L., Universidad Nacional de Tucumán, Tucumán.

Babot, M.P. 2007. Organización social de la práctica de molienda: casos actuales y prehispánicos del Noroeste argentino. En Procesos Sociales Prehispánicos en el Sur Andino: La Vivienda, la Comunidad y el Territorio, compilado por A. Nielsen, M. Rivolta, V. Seldes, M. Vazquez y P. Mercolli, pp. 259-290. Editorial Brujas, Córdoba.

Berberián, E. 1987. Crónicas del Tucumán. Siglo XVI. Comechingonia, Córdoba.

Bixio, B. y E. Berberián 2006-2009. Principios de análisis documental en arqueología. Xama 19-23:321-334.

Bouzo, C. 2009. El Cultivo de Papa en Argentina. Universidad Nacional del Litoral, Facultad de Ciencias Agrarias. http://www. ecofisiohort.com.ar/wp-content/uploads/2009/04/cultivo-depapa-en-argentina.pdf

Capparelli, A. 2007. Los productos alimenticios derivados de Prosopis chilensis (Mol.) Stuntz y P. flexuosa DC., Fabaceae, en la vida cotidiana de los habitantes del NOA y su paralelismo con el algarrobo europeo. Kurtziana 33 (1):1-19.Volumen especial de etnobotánica.
Capparelli, A. 2011. Elucidating post-harvest practices involved in the processing of algarrobo (Prosopis spp.) for food at El Shincal Ina site (Northwest Argentina): and experimental approach based on charred remains. Archaeological Anthropological Science 3:93-112.

Capparelli, A. y V. Lema 2011. Recognition of post-harvest processing of algarrobo (Prosopis spp.) as food from two sites of Northwestern Argentina: an ethnobotanical and experimental approach for desiccated macroremains. Archaeological and Anthropological Sciences 3:71-92.

Castro Olañeta, I. 2004. Transformaciones y Continuidades de Sociedades Indígenas en el Sistema Colonial. El Pueblo de Indio de Quilino a Principios del S. XVII. Alción Editora, Córdoba.

Colqui, E. 2015 Análisis del arte rupestre en el contexto de Cerro Colorado (Sierras del Norte, Córdoba). En Arqueogasta, Arqueología y Redes, editado por A. Robledo, pp. 43-46, Córdoba.

Cortella, A. y M. L. Pochettino 1995. Comparative morphology of starch of three Andean tubers. Starch/stärke 47 (12):455-461.

Fernández Pepi, M.G. 2013. Estudios Fitolíticos de las Comunidades Vegetales del Ecotono Fueguino como una Herramienta para Reconocer sus Variaciones de Composición en el Pasado Reciente. Tesis Doctoral, Facultad de Ciencias Exactas y Naturales, Universidad de Buenos Aires, Buenos Aires.

Gardner, G.A. 1930. Art Ethnographique. The Rock-Paintings of La Quebrada. Verlag, Buenos Aires.

Giovannetti, M., V.S. Lema, C.G. Bartoli y A. Capparelli 2008. Starch grain characterization of Prosopis chilensis (Mol.) Stuntz and P. Flexuosa DC, and the analysis of their archaeological remains in Andean South America. Journal of Archaeological Science 35:2973-2985. 
Gremillion, K. 1993 Crop and weed in prehistoric eastern North America: The Chenopodium example. American Antiquity 58:496-509.

Hastorf, C. y V. Popper 1988. Current Paleoethnobotany. Analytical Methods and Cultural Interpretations of Archaeological Plant Remains. The University of Chicago Press, Chicago.

Hoyos, L.E., A.M. Cingolani, M.R. Zak, M.V. Vaieretti, D.E. Gorla y M.R. Cabido 2012. Deforestation and precipitation patterns in the arid Chaco forests of central Argentina. Applied Vegetation Science. Doi: 10.1111/j.1654-109X.2012.01218.x

Huarte M.A. y S. Capezio 2015. Cultivo de Papa. Instituto Nacional de Tecnología Agropecuaria, Buenos Aires.

Johnston, R. 2005. A social archaeology of garden plots in the Bronze Age of northern and western Britain. World archaeology 37:211-223.

Korstanje, A. 2015. Andenes en los Andes: paisajes agrícolas tardíos sin maíz. En Racionalidades Campesinas en los Andes del Sur. Reflexiones en Torno al Cultivo de la Quinoa y Otros Vegetales Andinos, editado por P. Cruz, R. Joffre y T. Winkel, pp. 24-57. EDIUNJU, San Salvador de Jujuy.

Korstanje M.A. y M.P. Babot 2007. A microfossil characterization from South Andean economic plants. En Places, People and Plants: Using Phytoliths in Archaeology and Paleoecology (Proceeding of the 4th International Meeting on Phytolith Research), editado por M. Madella, M.K. Jones y D. Zurro, pp. 41-72. Oxbow Books, Cambridge.

Lagiglia, H. 2005. Un recurso alimenticio prehistórico. La quinoa en Cuyo (Chenopodium quinoa y especies afines a las familias de las Chenopodiáceas y Amaranthaceas). Notas del Museo $\mathrm{N}^{\circ}$ 56. Museo de Historia Natural de San Rafael, Mendoza.

Laguens, A. 1999. Arqueología del Contacto Hispano-Indígena. Un Estudio de Cambios y Continuidades en las Sierras Centrales de Argentina. BAR International Series 801, Oxford.

Lema, V. 2013. Criar y ser criados por las plantas y sus espacios en los Andes Septentrionales de la Argentina. En Espacialidades Altoandinas. Nuevos Aportes desde la Argentina. Tomo I: Miradas hacia lo Local, lo Comunitario y lo Doméstico, editado por A. Bendetti y J. Tomassi, pp. 301-338. Editorial de la Facultad de Filosofía y Letras, Universidad de Buenos Aires, Buenos Aires.

Llano, C. 2014. La explotación de los recursos vegetales en sociedades cazadoras-recolectoras de sociedades del sur de Mendoza, Argentina. Darwiniana 2 (1):96-111.

López, M.L. 2015. La cocina como medio para la reproducción social de los grupos prehispánicos de las sierras de Córdoba. En Condiciones de Posibilidad de la Reproducción Social en Sociedades Prehispánicas y Coloniales Tempranas en las Sierras Pampeana (República Argentina), compilado por J. Salazar, pp. 177-212. CEH Prof. Carlos S.A. Segreti, Córdoba.

López, M.L. 2017. Archaeobotany in Central Argentina. Macro and micro remains at several archaeological sites from early Late Holocene to early Colonial Times (3000-250 B.P.). Vegetation History and Archaeobotany. DOI: 10.1007/s00334-017-0627-x.

López, M.L., M. Medina y D. Rivero 2014. First records of Chenopodium spp./Amaranthus spp. starch grains and their relevance to the study of the late Holocene human subsistence in Central Argentina. The Holocene 25:288-295.

López, M.L., M.C. Bruno y M.T. Planella 2015. El género Chenopodium: Metodología aplicada a la identificación taxonómica en ejemplares arqueológicos. Presentación de casos de estudio de la región sur-andina. En Avances y Desafíos Metodológicos en Arqueobotánica: Miradas Consensuadas y Diálogos Compartidos desde Sudamérica, editado por C. Belmar y V.S. Lema, pp. 89121. Universidad Internacional SEK, Santiago.

López, L. y A. Recalde 2016. First quinoa (Chenopodium quinoa willd) botanical macro-remains at Sierras del Norte (Central Argentina) and its implications in pre-hispanic subsistence practices. Journal of Archaeological Science. Reports 8:426-433.

Madella, M., A. Alexandre y T. Ball 2005. International code for Phytolith Nomenclature 1.0. Annals of Botany 96:253-260.

Medina, M., S. Grill, A. Fernández y M.L. López 2017. Antropogenic pollen, foraging and crops during Sierras de Córdoba Late Prehispanic Period (Argentina). The Holocene. DOI: $10.1177 / 0959683617708445$.

Medina, M., S. Pastor y A. Recalde 2016. The archaeological landscape of Late Prehispanic mixed foraging and cultivation economy (Sierras of Cordoba, Argentina). Journal of Anthropological Archaeology 42:88-104.

Medina, M., S. Pastor y D. Rivero 2013. Osteometría y diferenciación de especies de camélidos en sitios arqueológicos de las Sierras Centrales (Argentina). Tendencias, problemas y perspectivas. Intersecciones en Antropología 15:339-251.

Montes, A. 2008. Indígenas y Conquistadores de Córdoba. Ediciones Isquitipe, Córdoba.

Oliszewski, N. 1999. La importancia del algarrobo en el Campo del Pucará (Andalgalá, Catamarca) durante el Período Formativo. En los Tres Reinos: Prácticas de Recolección en el Cono Sur de América, editado por C.A. Aschero, M.A. Korstanje y P.M. Vuoto, pp. 171-186. Ediciones Magna Publicaciones, Tucumán.

Oliszewski, N. 2008. Metodología para la identificación subespecífica de maices arqueológicos. Un caso de aplicación en el Noroeste de Argentina. En Arqueobotánica y Teoría Arqueológica. Discusiones desde Suramérica, editado por S. Archila, M. Giovannetti y V. Lema, pp. 181-202. UniandesCeso, Bogotá.

Pastor, S. 2015. Acerca de la constitución de agentes sociales, objetos y paisajes. Una mirada desde las infraestructuras de molienda (Sierras de Córdoba, Argentina). En Condiciones de Posibilidad de la Reproducción Social en Sociedades Prehispánicas y Coloniales Tempranas en las Sierras Pampeanas (República Argentina), compilado por J. Salazar, pp. 402-441. Centro de Estudios Históricos "Prof. S. A. Segreti”, Córdoba.

Pastor, S. y M.L. López 2011. Consideraciones sobre la agricultura prehispánica en el sector central de las sierras de Córdoba (Argentina). En Arqueología de la Agricultura: Casos de Estudio en la Región Andina Argentina, editado por M.A. Korstanje y M. Quesada, pp. 208-233. Ediciones Magna, Buenos Aires.

Pastor, S., M. Medina, A. Recalde, L. López y E. Berberián 2012. Arqueología de la región montañosa central de Argentina. Avances en el conocimiento de la historia prehispánica tardía. Relaciones de la Sociedad Argentina de Antropología XXXVII (1):89-112. 
Pearsall, D. 2015. Paleoethnobotany. A Handbook of Procedures. Academic Press, San Diego.

Perry, L. 2004. Starch analyses reveal the relationship between tool type and function: An example from the Orinoco valley of Venezuela. Journal of Archaeological Science 31:1069-1081.

Piovano, E.L., D. Ariztegui, F. Cordoba, M. Cioccale y F. Sylvestre 2009. Hydrological variability in South America below the Tropic of Capricorn (Pampas and Patagonia, Argentina) during the last $13.0 \mathrm{ka}$. En Past Climate Variability in South America and Surrounding Regions, Developments in Paleoenvironmental Research, editado por F. Vimeux, F. Sylvestre y M. Khodri, pp. 323-351. Springer, Dordrecht.

Piperno, D. 2006. Phytoliths. A Comprensive Guide for Archaeologists and Paleoecologists. Altamira Press, Oxford.

Piperno, D. e I. Holst 1998. The presence of starch grains on prehistoric stone tools from the Humid Neotropics: Indications of early tuber use and agriculture in Panama. Journal of Archaeological Science 25:765-776.

Ratto, N., V.S. Lema y M.L. López 2014. Entierros y ofrendas: prácticas mortuorias, agrícolas y culinarias en los siglos XIII y XIV en Tinogasta (Catamarca, Argentina). Darwiniana, nueva serie 2 (1):125-143.

Recalde, A. 2008-09. Movilidad estacional y representaciones rupestres. Primeras evidencias de ocupaciones estivales vinculadas con la explotación de ambientes chaqueños en las sierras de Córdoba. Anales de Arqueología y Etnología 63-64:57-80.

Recalde, A. 2015. Representaciones en contexto. Características del Paisaje rupestre de Cerro Colorado (Sierras del Norte, Córdoba, Argentina). Relaciones de la Sociedad Argentina de Antropología XL (2):523-548.

Riat, P. 2012. Conocimiento campesino, el "monte santiagueño" como recurso forrajero. Trabajo y Sociedad 19:477-491.

Rivero, D., M. Medina, A. Recalde y S. Pastor 2010. Variabilidad en la explotación de recursos faunísticos durante el Holoceno en las Sierras de Córdoba (Argentina): una aproximación zooarqueológica. En Zooarqueología a Principios del Siglo XXI: Aportes Teóricos, Metodológicos y Casos de Estudio, editado por M. Gutiérrez, M. De Nigris, P. Fernández, M. Giardina, A.
Gil, A. Izeta, G. Neme y H. Yacobaccio, pp. 321-331. Ediciones del Espinillo, Buenos Aires.

Scarpa, G. 2009. Wild food plants used by the indigenous peoples of the South American Gran Chaco. A general synopsis and intercultural comparison. Journal of Applied Botany and Food Quality 83:90-101.

Sciammaro, L. 2015. Caracterización Fisicoquímica de Vainas y Harina de Algarrobo (Prosopis alba y Prosopis nigra). Aplicaciones en Productos Horneados y Fermentados. Tesis Doctoral. Universidad Nacional de La Plata, La Plata.

Trillo, C. 2010. Valoración del Bosque y Conocimiento de las Plantas Silvestres por Parte de los Pobladores de las Sierras de Guasapampa, Noroeste de la Provincia de Córdoba. Tesis Doctoral, Facultad de Ciencias Exactas Físicas y Naturales, Universidad Nacional de Córdoba, Córdoba.

Trillo, C. 2016. Prácticas tradicionales de manejo de recursos vegetales en unidades de paisajes culturales del oeste de la provincia de Córdoba, Argentina. Zonas Áridas 16 (1):86-111.

Trillo, C., B. Arias Toledo, L. Galetto y S. Colantonio 2010. Persistence of the Use of Medicinal Plants in Rural Communities of the Western Arid Chaco [Córdoba, Argentina]. The Open Complementary Medicine Journal 2:80-89.

Trillo, C. y P. Demaio 2007. Tintes Naturales. Guía para el Reconocimiento y Uso de Plantas Tintóreas del Centro de Argentina. Sezo, Córdoba.

Twiss, P., E. Suess y R. Smith 1969. Morphological classification of grass phytoliths. Soil Science Society of America, Proceeding 33:109-115.

Villagra, P., M. Cony, N. Mantován, B. Rossi, M. González, R. Villalba y L. Marone 2004. Ecología y manejo de los algarrobales de la Provincia Fitogeográfica del Monte. En Ecología y Manejo de Bosques Nativos de Argentina, editado por M.F. Arturi, J.L. Frangi y J.F. Goya, pp. 1-32. Editorial Universidad Nacional de La Plata, La Plata.

Zak, M.R. y M. Cabido 2002. Spatial patterns of Chaco vegetation of central Argentina: Integration of remote sensing and phytosociology. Applied Vegetation Science 5:213-226.

\section{Notas}

1 En la arqueología regional identificamos algunos rasgos que nos permiten asignar una cronología relativa. Respecto al PPT (ca. 400-1550 d.C.) la presencia de tecnología cerámica y de pequeñas puntas de proyectil triangulares con pedúnculo y aletas aluden a un momento tardío en el proceso histórico local.

2 Las ocupaciones residenciales o poblados del período Prehispánico Tardío no están definidos en la arqueología regional por estructuras arquitectónicas visibles o permanentes. Por el contrario, pueden ser identificados a nivel superficial por una densa concentración de artefactos distribuidos en terrenos asociados a espacios potencialmente cultivables. Las únicas características a nivel estratigráfico son el piso habitacional, las huellas o negativos de poste de la estructura que sostuvo los techos y los fogones, estos últimos frecuentemente informales, dado que no están delimitados (Medina et al. 2016).

3 Aunque no se puede descartar la presencia de Lama glama no se cuenta hasta el momento con evidencia que acredite la existencia de esta especie en la región y, en consecuencia, las prácticas asociadas, dado que los resultados osteométricos indican un solo taxón en los conjuntos arqueológicos (Lama cf. L. guanicoe). Concomitante con esto, los estudios destacan la falta de aplicabilidad de otros indicadores usados para la identificación de L. glama (v.gr. las fibras no se conservan en el registro arqueológico) (Medina et al. 2014). 